\title{
Catalytic Hydrodeoxygenation of Lignin-Derived Feedstock Into Arenes and Phenolics
}

\author{
Yaxuan Jing and Yanqin Wang * \\ Shanghai Key Laboratory of Functional Materials Chemistry, School of Chemistry and Molecular Engineering, Research \\ Institute of Industrial Catalysis, East China University of Science and Technology, Shanghai, China
}

\section{OPEN ACCESS}

Edited by:

Guanghui Zhang,

Dalian University of Technology, China

Reviewed by:

Lei Bai,

West Virginia University, United States

Feng Wang,

Chinese Academy of Sciences, China

*Correspondence:

Yanqin Wang

wangyanqin@ecust.edu.cn

Specialty section:

This article was submitted to

Catalytic Engineering,

a section of the journal

Frontiers in Chemical Engineering

Received: 30 June 2020

Accepted: 31 July 2020

Published: 11 September 2020

Citation:

Jing $Y$ and Wang $Y$ (2020) Catalytic Hydrodeoxygenation of Lignin-Derived

Feedstock Into Arenes and Phenolics.

Front. Chem. Eng. 2:10

doi: 10.3389/fceng.2020.00010
Lignin, as the only most abundant aromatic source in nature, shows great potential to address environmental and energy problems. Hydrodeoxygenation (HDO), as a useful way of converting lignin and its derived compounds into value-added aromatic chemicals and fuels, is able to transform the vision "fueling the future" into reality, thus garnering considerable attention in the past decade. The purpose of this minireview is to specifically address the removal of phenolic hydroxyl groups and/or methoxy groups within lignin, mainly focusing on the core questions and challenges of catalytic systems. Our own insights into future studies and recommendations for future research in this promising field are also provided.

Keywords: lignin, hydrodeoxygenation, C-O cleavage, arenes, phenol

\section{INTRODUCTION}

Research in catalytic conversion of biomass has intensified in recent years due to the reduction of non-renewable fossil resources and the pressing need for global warming mitigation (Shuo et al., 2018; Jing et al., 2019a; Sudarsanam et al., 2019; Mondelli et al., 2020). Among three constituents (cellulose, hemicellulose, and lignin) of lignocellulosic biomass, lignin, as the most abundant source of aromatics in nature, is an attractive frontier in biomass chemistry and have achieved encouraging progress (Shuai et al., 2016; Sun et al., 2018a; Zhang and Wang, 2020). The extended network of lignin is constructed from methoxylated phenylpropanoid subunits via intermolecular $\mathrm{C}-\mathrm{O}$ and C-C bonds (Cai et al., 2019; Jing et al., 2020). However, the high content of oxygen in lignin makes it less attractive as a chemical material compared to petroleum; thus, the proper cleavage of C-O bonds is essential for lignin valorization (Zhang et al., 2017; Sun et al., 2018b; Kim et al., 2019). Indeed, the past decade has seen a rapid development of research on the hydrodeoxygenation (HDO) of lignin and its derived compounds (Sudarsanam et al., 2018; Duan et al., 2019; Kim et al., 2019). Nevertheless, the efficient and selective cleavage of $\mathrm{C}-\mathrm{O}$ bonds in lignin is difficult due to the complexity and recalcitrance of lignin, so that advanced multifunctional catalysts, especially a combination of metal sites and acidic supports, is usually required to produce a desirable outcome (Jin et al., 2019; Song et al., 2019).

Among various intermolecular $\mathrm{C}-\mathrm{O}$ bonds within lignin, the $\mathrm{C}-\mathrm{O}$ bond energy in aryl ethers is strong, especially for that in phenol, making their cleavage very difficult (Shao et al., 2017). When aiming to the production of aromatic compounds, such as arenes and phenol, advanced catalysts capable of selectively cleaving the corresponding $\mathrm{C}-\mathrm{O}$ bonds while preserving the aromatic rings are highly desirable. The selectivity of arenes and phenol is affected by various key factors, such as intrinsic oxophilicity, adsorption geometry, geometric effects, and electronic effects. Around these, this minireview specifically handles the removal of phenolic hydroxyl groups and/or 
methoxy groups within lignin (Figure 1). Our goal is not to provide a comprehensive overview of the cleavage of $\mathrm{C}-\mathrm{O}$ bonds; rather, core questions and challenges related to this piece and requirements for future investigations are presented. Meanwhile, some personal perspectives and future directions are provided. At last, the emphasis is given to several large challenges within this promising field.

\section{THE REMOVAL OF PHENOLIC HYDROXYL GROUPS TO ARENES}

The removal of phenolic hydroxyl groups of lignin to arenes is extremely challenging due to the evident competition between the excessive hydrogenation of benzene rings and the cleavage of phenolic $\mathrm{C}-\mathrm{O}$ bonds. From lignin model compounds to arenes, taking phenol as an example, three different reaction mechanisms were proposed, namely, the direct hydrogenolysis of phenolic hydroxyl groups, hydrogenation-dehydration-dehydrogenation route, and tautomerization-hydrogenation-dehydration route (Jin et al., 2019). Many studies have confirmed that the hydrogenolysis ability of metal sites is a key factor for the removal of phenolic hydroxyl groups to arenes, and a proper hydrogenation activity is of importance to maximize the selectivity to arenes (Gazi, 2019). If too strong, it causes the saturation of the aromatic ring, but if too weak, oxygen cannot be completely removed. Around the hydrogenolysis ability, electronic, and geometric structures of catalysts for improving the selectivity to arenes were research hotspots. The particle size plays a key role, and it not only affects the activity of the C-O cleavage but also is able to determine the selectivity to aromatic compounds (Figure 2). For example, the small-sized Ru afforded higher selectivity to aromatic compounds due to the decreased barriers for the cleavage of both $\mathrm{C}_{\text {aliphatic }}-\mathrm{O}$ and $\mathrm{C}_{\text {aromatic }}-\mathrm{O}$ bonds compared to these $\mathrm{Ru}$ species with larger particle size (Dong et al., 2018). The co-adsorption of aromatic ring and $\mathrm{H}_{2}$ is recognized as the prerequisite to drive the hydrogenation of aromatic ring, and the limited surface area of small $\mathrm{Ru}$ species prevents the co-adsorption owing to the higher barrier for the adsorption of aromatic ring on small $\mathrm{Ru}$ species than that of flat surfaces (Nelson et al., 2015; Sanyal et al., 2019; Singh et al., 2020). Decreasing the Ni particle size was also proved to be favorable for the increase of defect sites, thus improving the reactivity of selective deoxygenation into toluene (Yang et al., 2018). Generally, the particle size is positively associated with coordination numbers (C.N.), and establishing size selectivity or C.N. selectivity relationship could have the great potential to inspire catalyst design toward the $\mathrm{C}-\mathrm{O}$ cleavage of lignin and its

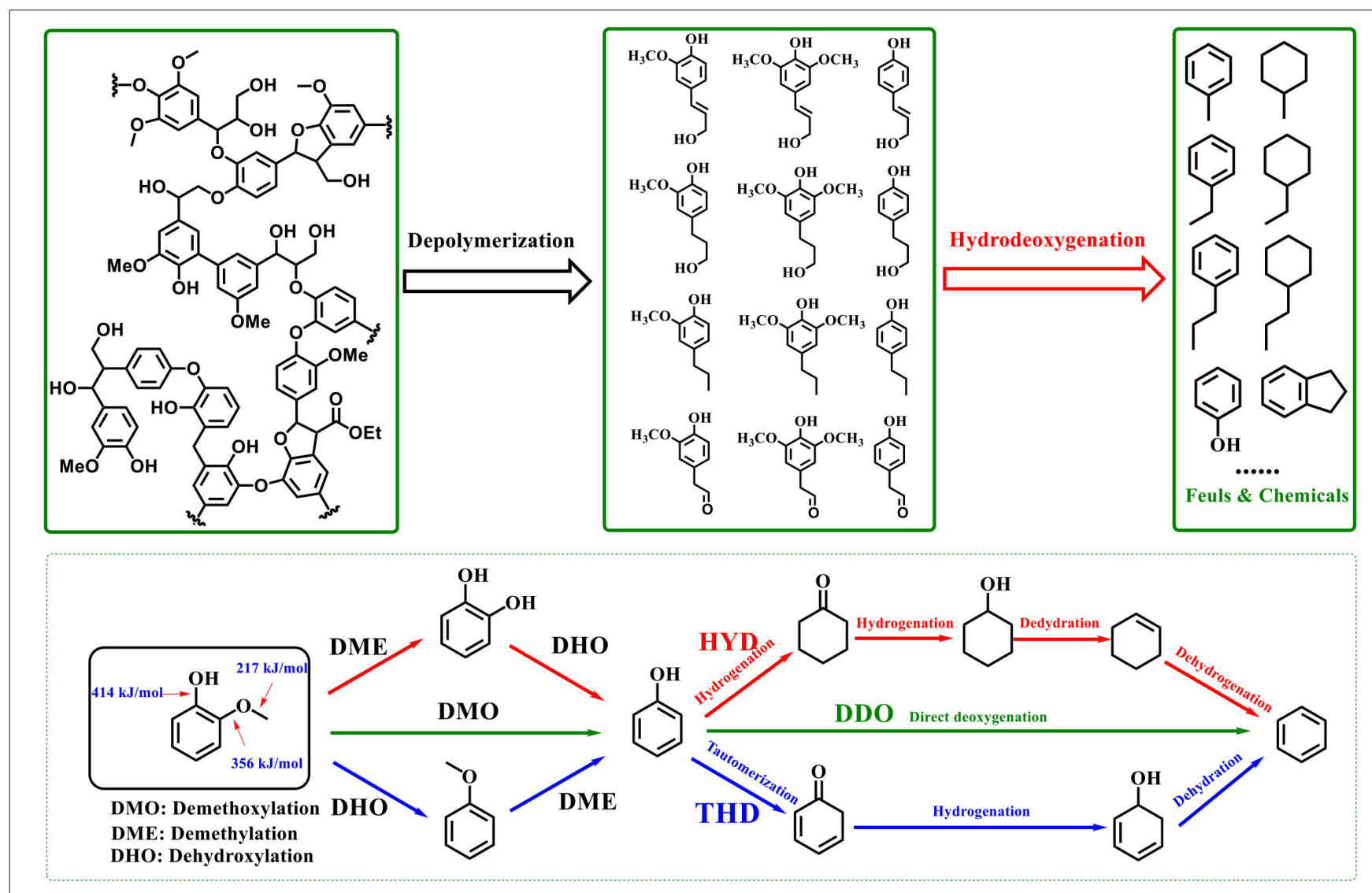

FIGURE 1 | Reaction network for the conversion of lignin and its derived compounds. 
derived compounds. Besides the particle size, the selectivity of hydrogenolysis also depends on the surface adsorption geometry. For example, the bonding of anisole on Pt (111) with a flat orientation facilitated the ring saturation, while after modifying Pt (111) with $\mathrm{Zn}$, the adsorption of oxygen on $\mathrm{Zn}$ or adjacent Pt sites occurred with the ring tilted away, resulting in a distinct selectivity to aromatic compounds (Shi et al., 2016). Actually, there exist similarity and difference between adsorption geometry and geometry effects. For example, the small-sized particle with high dispersion of metal favors the selectivity of arenes, which belongs to the influence of the geometric effect. Its deeper reason is that the limited surface area of the small particle prevents the co-adsorption of aromatic ring and $\mathrm{H}_{2}$, which belongs to the influence of the adsorption geometry. Establishment of a clear

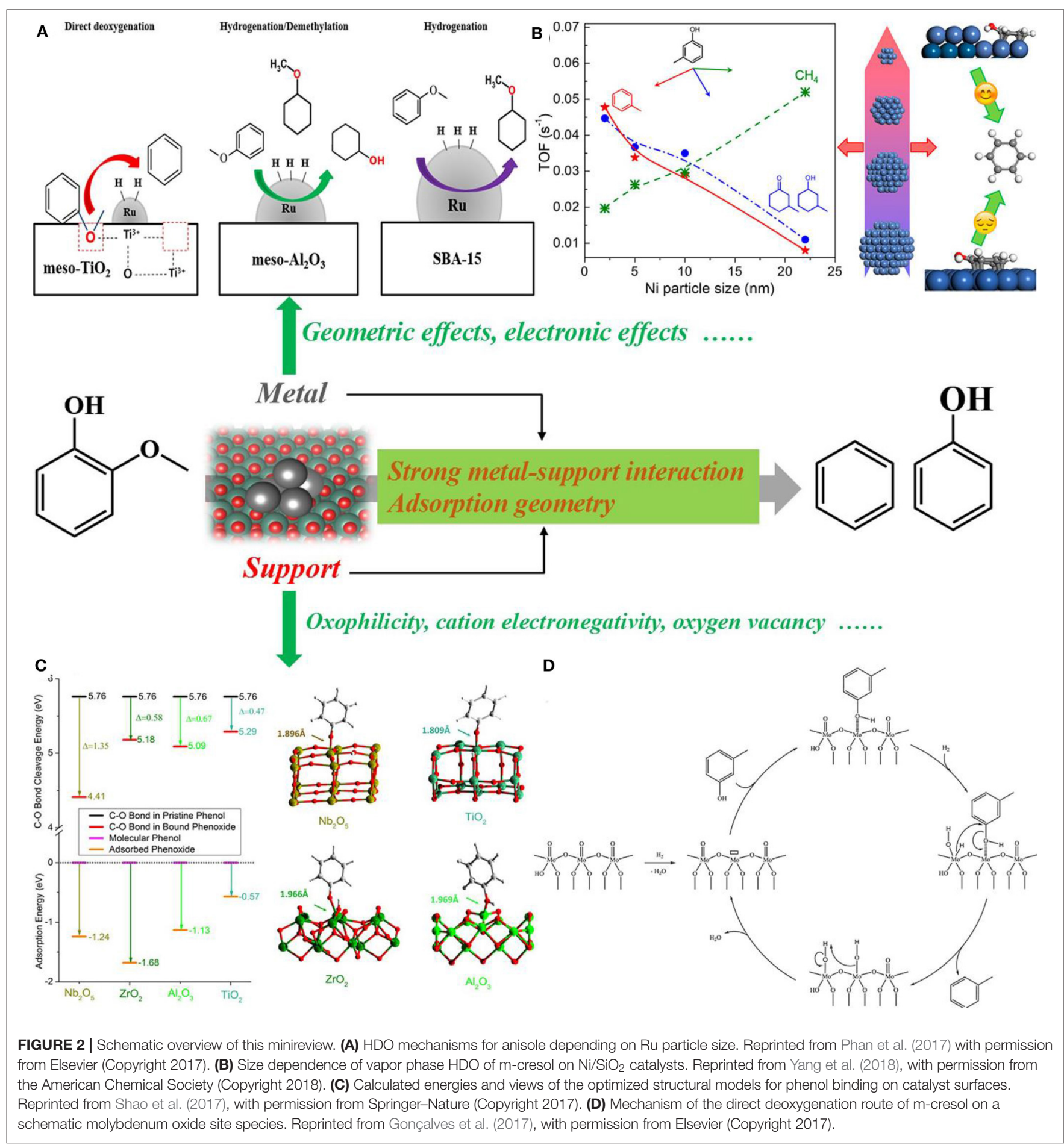


relationship between adsorption geometry and geometry effects is highly desirable in future.

In addition to the hydrogenation sites, supports containing oxophilic sites are of significant importance for the $\mathrm{C}-\mathrm{O}$ cleavage (Figure 2). Oxophilicity describes the ability of abstracting $\mathrm{O}$ from oxygenated compounds, and the oxygen affinity to activate $\mathrm{C}-\mathrm{O}$ bonds is an essential factor for high HDO efficiency. Oxophilic metal oxides with strong Lewis acidity including $\mathrm{NbO}_{\mathrm{x}}, \mathrm{MoO}_{\mathrm{x}}, \mathrm{TiO}_{\mathrm{x}}, \mathrm{ReO}_{\mathrm{x}}, \mathrm{WO}_{\mathrm{x}}, \mathrm{TaO}_{\mathrm{x}}$, and $\mathrm{VO}_{\mathrm{x}}$ have attracted intensive attention (Xia et al., 2016; Dong et al., 2019a; Liu S. et al., 2019). The activation step is generally accomplished via the formation of covalent bonds along with strong chemisorption. A compelling example is that the super-strong oxygen affinity of $\mathrm{NbO}_{\mathrm{x}}$ species contributed to a strong ability to activate oxygen within lignin, along with the Ru hydrogenation site, cooperatively resulting in excellent HDO performance (Shao et al., 2017). This unique oxygen affinity was also clear to see in other C$\mathrm{O}$ bond cleavage, especially on the $\mathrm{C}-\mathrm{O}$ bond cleavage of the tetrahydrofuran ring and the $\mathrm{C}=\mathrm{O}$ bond activation to enolate intermediate (Jing et al., 2019b; Wang et al., 2020). Actually, these oxophilic metal oxides are all transition metal oxides, especially the group IV B, V B, VI B, and VII B elements. While several oxophilic species, such as $\mathrm{NbO}_{\mathrm{x}}, \mathrm{ReO}_{\mathrm{x}}$, and $\mathrm{MoO}_{\mathrm{x}}$, have been identified and extensively studied, there is no consensus on the sequence or the origin of the oxophilic ability. These oxygen-rich phenolic compounds are rich in electron from the point view of electronic effect. Whether these oxophilic species are more electron-deficient than the others is still in question, and if yes, these oxophilic species may possess stronger Lewis acidity. However, previous studies have proved that the catalytic performance is not completely consistent with the sequence of Lewis acidity (Jing et al., 2019b). Lewis acidity was mainly measured by Py-FTIR spectra in the reported literature, so that Lewis acidity of these materials can be understood as its strong adsorption to pyridine, but not sure whether these materials can adsorb oxygenates in the same sequence. $\mathrm{C}-\mathrm{O}$ bond elongation of adsorbed phenol was found to be associated positively with the increased oxophilicity: $\mathrm{Ni}<\mathrm{Fe} \approx \mathrm{Co} \approx \mathrm{Mn}<\mathrm{Re}<\mathrm{Mo}$ $\approx \mathrm{Cr}<\mathrm{W} \approx \mathrm{V} \approx \mathrm{Sc}<\mathrm{Ti}$ (Phan et al., 2017), which further confirms the significance of oxophilicity in the $\mathrm{C}-\mathrm{O}$ cleavage. If a thorough understanding of the oxophilicity is garnered from theoretical and experimental analyses, catalyst design toward the HDO reaction will be improved to a new level in future. Besides, coordination states of metal oxides also have a strong influence and metal oxides with lower coordination numbers or more unsaturated surface groups were proven to be beneficial for the HDO reaction, accordingly giving additional guidance on how to design efficient catalysts (Xin et al., 2019a).

The surface reaction of the direct hydrogenolysis of phenolic hydroxyl groups goes to the adsorption of phenol, activation cleavage of the $\mathrm{C}-\mathrm{O}$ bond, and desorption of benzene. The efficient catalyst should therefore enable strong adsorption to oxygen within phenol, strong activation to the $\mathrm{C}-\mathrm{O}$ bond, and weak adsorption to benzene. $\mathrm{Ru} / \mathrm{Nb}_{2} \mathrm{O}_{5}$ meets the three conditions well, especially the stronger activation to the $\mathrm{C}-\mathrm{O}$ bond, affording the unique activity (Shao et al., 2017). Actually, strong adsorption-activation to the $\mathrm{C}-\mathrm{O}$ bond requires that the catalyst has an excellent oxophilic property, where the catalyst prefers the bonding via the oxygen lone-pair electrons on the oxophilic site with the benzene ring tilted away from the surface, rather than the $\pi$-orbitals of the phenyl ring with the ring situated parallel. Indeed, there is a close relationship between the adsorption geometry and the oxophilic property, synergically determining the selectivity of products. Though it si hard to adjust the adsorption configuration by introducing oxophilic species into the catalyst, keeping the same adsorption configuration to compare the oxophilic property is still worth giving more attention toward catalyst design. A striking example is that, adsorption configuration being the same over Fe (110), $\mathrm{Pt}$ (111), and $\mathrm{Ru}$ (0001), the higher oxophilicity of Fe contributes to a lower activation barrier for the $\mathrm{C}-\mathrm{O}$ cleavage than that of $\mathrm{Pt}$ and $\mathrm{Ru}$, affording unique selectivity to arenes (Tan et al., 2017). Moreover, the first principle is capable of understanding the adsorption of the key species, here oxygen and aromatic ring, where the $\mathrm{Fe}$ surface presents a greater distortion of the $\mathrm{C}-\mathrm{O}$ bonds while the Pd surface has a strong interaction with the aromatic ring, potentially guiding the catalyst design (Hensley et al., 2016). Along this line, developing the more oxophilic species with preferable adsorption geometry tends to be the great drive to produce arenes and vice versa for the production of ring-saturated products. It is worth noting that some advanced catalysts can work well in vapor-phase systems but lose their reactivity in liquid-phase systems ( $\mathrm{Li}$ et al., 2017). The difference between both systems may originate from different surface adsorption configurations, even different surface reaction mechanisms. Further development will be encouraged to design active catalysts toward different reaction systems, whether liquid phase or vapor phase, and possibly assist reactor design.

Since lignin and its monomers are rich in functional groups, the cleavage of $\mathrm{C}-\mathrm{O}$ bonds usually accompanied by several competition reactions, such as dehydrogenation of para-propyl hydroxyl group, dehydrogenative decarbonylation, intramolecular cyclization reaction, and $\mathrm{C}-\mathrm{C}$ hydrogenolysis (Li H. et al., 2020). These competitive pathways highly depend on the types of metals, hydrogenation/hydrogenolysis ability, and acid properties of supports. For example, letting the intramolecular cyclization goes first before the cleavage of $\mathrm{C}-\mathrm{O}$ bonds over the $\mathrm{CH}_{2} \mathrm{Cl}_{2}$-modified $\mathrm{Ru} / \mathrm{Nb}_{2} \mathrm{O}_{5}$ catalyst could stand a chance for the production of indane and its derivates from lignin (Xin et al., 2019b). Again, through introducing $\mathrm{FeO}_{\mathrm{x}}$ species into the $\mathrm{Ru} / \mathrm{Nb}_{2} \mathrm{O}_{5}$ catalyst, dehydrogenative decarbonylation competes favorably with the direct hydrogenolysis of terminal hydroxypropyl groups, achieving a unique selectivity to ethylbenzene ( $\mathrm{Li} \mathrm{H}$. et al., 2020). The two recent examples prove that, indeed, manipulating the reaction pathways through the design of catalysts with well-defined tasks enables the production of novel chemicals. In this piece, despite these recent efforts, other state-of-theart strategies for catalyst modification and novel reaction process for the production of new chemicals remain to be encouragingly explored. 


\section{SELECTIVE CLEAVAGE OF C-O BONDS INTO PHENOLICS}

Although renewable biobased alkanes and arenes are attractive substitutes of petroleum-based transportation fuels, catalytic HDO of lignin to low-functionalized arenes, and alkanes lose the diversity of functional groups (Huang et al., 2018). Selective or partial cleavage of $\mathrm{C}-\mathrm{O}$ bonds to high-functionalized chemicals has thus attracted great interest recently and is believed to be a dynamic research direction in future. For example, the production of phenol from lignin or lignin model compounds through selectively removing the methoxy groups and paraside-chain groups, but preserving the phenolic hydroxyl groups, has been intensively explored in the past 3 years (Figure 2) (Liao et al., 2020). Two common pathways, namely, direct demethoxylation and demethylation-dehydroxylation pathway, were accordingly proposed and greater interest focused on the demethoxylation mechanism. However, the final conclusion has not yet been reached on this question "how does structure and properties of catalysts affect the mechanism." We believe that the well-performing experience of "from lignin to arenes" could help to answer this question, and the researchers are striving to lift the veil (Jin et al., 2019; Jing et al., 2020).

Supported gold catalysts showed excellent catalytic performance with high phenolic selectivity, and the particle size of Au markedly affects the catalytic activity (Mao et al., 2017). The catalyst with smaller Au particles contributed to a higher activity due to its larger interface area between small gold particles and the support than that of larger Au particles. Actually, the size effect of $\mathrm{Au}$ was well-established in some traditional catalytic systems, such as CO oxidation, and nanoparticles (>2 nm), cluster $(<2 \mathrm{~nm})$, and single atoms showed different performance because of the significant difference of the coordination environment of Au on the interface (Ishida et al., 2019). Studies need to be done for the comprehensive understanding of $\mathrm{Au}$ size effect in the cleavage of the methoxy groups, for example to explore the surface adsorption geometry on the catalysts bearing different $\mathrm{Au}$ particle sizes. The electronic effect of $\mathrm{Au}$ also has a distinguished effect in the demethoxylation, and the electronrich $\mathrm{Au}$ clusters give the remarkable selectivity to phenolics (Dong et al., 2019b).

Oxygen vacancy of support as the active site also plays a key role in the selective conversion of guaiacol into phenol. Silver initiated hydrogen spillover on anatase $\mathrm{TiO}_{2}$ to create more oxygen vacancy as active sites, meanwhile weaker hydrogenation activity of Ag favors the production of aromatic compounds, accordingly showing the excellent performance for the selective conversion of guaiacol into phenol (Liu K. et al., 2019). Indeed, not just in the cleavage of the methoxy groups, the formation of oxygen vacancy is of significant importance for C-O cleavage chemistry of biomass. The metal capable of motivating hydrogen spillover on the oxophilic support to create oxygen vacancy remains mostly unexplored. After achieving this, keeping oxygen vacancy abundant to obtain high activity of $\mathrm{C}-\mathrm{O}$ cleavage, selecting the metal sites with different hydrogenation ability will yield different target products.
In addition, the support with higher cation electronegativity is believed to be responsible for the efficient cleavage of $\mathrm{O}-\mathrm{CH}_{3}$ bonds (Zhang et al., 2018; Song et al., 2020). Mo-base catalysts $\left(\mathrm{MoO}_{3} / \mathrm{SiO}_{2}, \mathrm{MoO}_{3} / \mathrm{CeO}_{2}, \mathrm{MoO}_{3} / \mathrm{Al}_{2} \mathrm{O}_{3}\right.$, $\mathrm{MoO}_{3} / \mathrm{TiO}_{2}$, and $\left.\mathrm{MoO}_{3} / \mathrm{AC}\right)$ are also active catalytic systems for the demethoxylation and support with higher cation electronegativity; here $\mathrm{MoO}_{3} / \mathrm{SiO}_{2}$ is believed to be responsible for the cleavage of the $\mathrm{O}-\mathrm{CH}_{3}$ bond. This electronegativity effect poses a question whether the cleavage of other $\mathrm{C}-\mathrm{O}$ bonds follows the same activity-to-electronegativity relationship over those reported catalysts, and future research is strongly encouraged in this direction. Around this piece, Sels and coworkers (Liao et al., 2020) described an engineering-guided wood biorefinery strategy involving reductive catalytic fractionation, extraction of phenolic monomers, and catalytic funneling for low-carbon footprint chemical production. This integrated biorefinery achieves several value-added chemicals and their precursors including phenol, propylene, phenolic oligomers, and carbohydrate pulp, showing a great potential to make renewable and profitable chemicals from waste biomass. Until now, the researchers studied separately the effects of support (oxophilicity, oxygen vacancy, cation electronegativity, etc.), and a clear comparison of these key properties is highly desirable despite the great difficulty. However, before comparing a key property, excluding the influence of others has to be conducted for the establishment of a more convincing conclusion.

A key challenge is that transmethylation products can be unavoidably formed, resulting in a low selectivity to phenolics. Two remarkable strategies were proposed to overcome this challenge: one is that water was employed as a quenching agent to prevent the transmethylation reaction (Dong et al., 2019b); another is that the methoxy groups were reacted to generate value-added alkylbenzenes using benzene as the reaction medium and reactant (Huang et al., 2018). Any work along this line will motivate the development of utilization efficiency of carbon in lignin, and novel strategies of methoxy group conversion need to be explored. Unlike transportation fuels, the value of phenol and other-related chemicals highly depends on purity. A remaining open question for further consideration is thus how to obtain desired products in super purity.

\section{PERSPECTIVE}

Apart from the abovementioned removal of phenolic hydroxyl groups and/or methoxy groups, many efforts were also devoted to studying cleavage of other $\mathrm{C}-\mathrm{O} / \mathrm{C}-\mathrm{C}$ bonds, such as $\beta-\mathrm{O}-4$, $4-\mathrm{O}-5$, and $\beta-5$. Especially, the cleavage of $\beta-\mathrm{O}-4$ linkage in lignin depolymerization has received great attention as it presents the largest number among native lignin (Van den Bosch et al., 2015; Ren et al., 2019). Although the cleavage of these $\mathrm{C}-\mathrm{O} / \mathrm{C}-\mathrm{C}$ bonds is not mentioned here, thorough investigation is still needed in the future. Here, we propose some following directions where the cleavage of $\mathrm{C}-\mathrm{O} / \mathrm{C}-\mathrm{C}$ bonds deserves further exploration. (1) Since most reported processes of $\mathrm{C}-\mathrm{O}$ bond cleavage cause inevitably loss of atoms in 
biomass, establishment of atom-economical strategies is highly desirable in the future. For example, the transformation of methoxy groups into chemicals is attractive to maximize carbon utilization efficiency in lignin (Mei et al., 2017). Apart from chemical production, using the methoxy groups or hydroxy groups in lignin as hydrogen sources to realize self-supported HDO through a combination of reforming/hydrogen transfer and HDO is atom-economic and is worth considerable attention. (2) The solid-solid contact problem between solid catalysts and recalcitrant biomass-related feedstocks remains a longterm challenge. The recalcitrance and insolubility originate from the strong hydrogen bonding networks generated by hydroxyl groups within biomass. Therefore, breaking or tuning these hydrogen-bonding networks to increase its solubility through designing advanced ionic liquids and organic solvents is worth great attention. In addition, catalyst design and pretreatment method of feedstocks to promote the mass transfer still need further exploration and study. (3) Attention was mainly paid to the research on the structure-activity relationship of catalysts and reaction mechanism; however, exploration on the influence of water received less attention. Water, as a green solvent, was found to be active to co-catalyze the cleavage of the C$\mathrm{O}$ bond within phenol (Nelson et al., 2015). Water adsorbed on hydroxylated or partially reduced $\mathrm{TiO}_{2}$ species is able to accept and/or donate protons through the $\mathrm{Ru} / \mathrm{TiO}_{2}$ interface to reduce the barrier for the removal of the phenolic $\mathrm{OH}$ group. Since the HDO process can produce water, thus further developments of co-catalytic roles bonding with other catalytic systems for the HDO of lignin are strongly encouraged. (4)

\section{REFERENCES}

Cai, Z. P., Long, J. X., Li, Y. W., Ye, L., Yin, B. L., France, L. J., et al. (2019). Selective production of diethyl maleate via oxidative cleavage of lignin aromatic unit. Chem. 5, 2365-2377. doi: 10.1016/j.chempr.2019.05.021

Dong, L., Lin, L. F., Han, X., Si, X. Q., Liu, X. H., Guo, Y., et al. (2019a). Breaking the limit of lignin monomer production via cleavage of interunit carbon-carbon linkages. Chem. 5, 1521-1536. doi: 10.1016/j.chempr.2019.03.007

Dong, L., Xin, Y., Liu, X. H., Guo, Y., Pao, C. W., Chen, J. L., et al. (2019b). Selective hydrodeoxygenation of lignin oil to valuable phenolics over $\mathrm{Au} / \mathrm{Nb}_{2} \mathrm{O}_{5}$ in water. Green Chem. 21, 3081-3090. doi: 10.1039/C9GC00327D

Dong, L., Yin, L. L., Xia, Q. N., Liu, X., Gong, X. Q., and Wang, Y. (2018). Size-dependent catalytic performance of ruthenium nanoparticles in the hydrogenolysis of a beta-O-4 lignin model compound. Catal. Sci. Technol. 8, 735-745. doi: 10.1039/C7CY02014G

Duan, H., Liu, J. C., Xu, M., Zhao, Y., Ma, X. L., Dong, J., et al. (2019). Molecular nitrogen promotes catalytic hydrodeoxygenation. Nat. Catal. 2, 1078-1087. doi: 10.1038/s41929-019-0368-6

Elangovan, S., Afanasenko, A., Haupenthal, J., Sun, Z., Liu, Y., Hirsch, A. K. H., et al. (2019). From wood to tetrahydro-2-benzazepines in three waste-free steps: modular synthesis of biologically active lignin-derived scaffolds. ACS Cent. Sci. 5, 1707-1716. doi: 10.1021/acscentsci.9b00781

Gazi, S. (2019). Valorization of wood biomass-lignin via selective bond scission: a minireview. Appl. Catal. B 257:117936. doi: 10.1016/j.apcatb.2019.117936

Gonçalves, V. O. O., Ciotonea, C., Arrii-Clacens, S., Guignard, N., Roudaut, C., Rousseau, J., et al. (2017). Effect of the support on the hydrodeoxygenation of m-cresol over molybdenum oxide based catalysts. Appl. Catal. B 214, 57-66. doi: 10.1016/j.apcatb.2017.05.003
Inherently abundant functional groups within lignin endow great opportunities to serve as potential substrates for the production of new value-added chemicals and biologically active molecules. Manipulating the reaction pathways through design advanced catalysts and benign solvents has significant potential to achieve this target (Elangovan et al., 2019; Xin et al., 2019b; Li L. et al., 2020). For example, employing $\mathrm{CH}_{2} \mathrm{Cl}_{2}$ to weaken the hydrogenolysis ability of metal $\mathrm{Ru}$, the generated strong interaction between both species favors the intramolecular cyclization reaction, rather than the competitive hydrogenolysis, giving a high selectivity of indane and its derivatives (Xin et al., 2019b). Making renewable chemicals and biologically active compounds along this line will increase the attraction of lignin valorization.

\section{AUTHOR CONTRIBUTIONS}

YJ and YW discussed the topic and wrote the manuscript together. All authors contributed to the article and approved the submitted version.

\section{FUNDING}

This work was supported financially by the NSFC of China (Nos. 21832002, 21872050, 21808063, 91545103, and 21603072), the Fundamental Research Funds for the Central Universities (222201718003 and 222201817022), and the Science and Technology Commission of Shanghai Municipality (10dz2220500).

Hensley, A. J., Wang, Y., and McEwen, J. S. (2016). Adsorption of guaiacol on Fe (110) and Pd (111) from first principles. Surf. Sci. 648, 227-235. doi: $10.1016 /$ j.susc. 2015.10 .030

Huang, X., Ludenhoff, J. M., Dirks, M., Ouyang, X., Boot, M. D., and Hensen, E. J. M. (2018). Selective production of biobased phenol from lignocellulose-derived alkylmethoxyphenols. ACS Catal. 8, 11184-11190. doi: 10.1021 /acscatal.8b03430

Ishida, T., Murayama, T., Taketoshi, A., and Haruta, M. (2019). Importance of size and contact structure of gold nanoparticles for the genesis of unique catalytic processes. Chem. Rev. 120, 464-525. doi: 10.1021/acs.chemrev.9b 00551

Jin, W., Pastor-Perez, L., Shen, D. K., Sepulveda-Escribano, A., Gu, S., and Reina, T. R. (2019). Catalytic upgrading of biomass model compounds: novel approaches and lessons learnt from traditional hydrodeoxygenation-a review. ChemCatChem 11, 924-960. doi: 10.1002/cctc.201801722

Jing, Y., Dong, L., Guo, Y., Liu, X., and Wang, Y. (2020). Chemicals from lignin: a review of the catalytic conversion involving hydrogen. ChemSusChem. doi: 10.1002/cssc.201903174. [Epub ahead of print].

Jing, Y., Guo, Y., Xia, Q., Liu, X., and Wang, Y. (2019a). Catalytic production of value-added chemicals and liquid fuels from lignocellulosic biomass. Chem 5, 2520-2546. doi: 10.1016/j.chempr.2019.05.022

Jing, Y., Xin, Y., Guo, Y., Liu, X., and Wang, Y. (2019b). Highly efficient $\mathrm{Nb}_{2} \mathrm{O}_{5}$ catalyst for aldol condensation of biomass-derived carbonyl molecules to fuel precursors. Chin. J. Catal. 40, 1168-1177. doi: 10.1016/S1872-2067(19)63371-1

Kim, S., Kwon, E. E., Kim, Y. T., Jung, S., Kim, H. J., Huber, G. W., et al. (2019). Recent advances in hydrodeoxygenation of biomass-derived oxygenates over heterogeneous catalysts. Green Chem. 21, 3715-3743. doi: 10.1039/C9GC01210A 
Li, H., Bunrit, A., Li, N., and Wang, F. (2020). Heteroatom-participated lignin cleavage to functionalized aromatics. Chemi. Soc. Rev. 49, 3748-3763. doi: 10.1039/D0CS00078G

Li, L. X., Dong, L., Liu, X. H., Guo, Y., and Wang, Y. Q. (2020). Selective production of ethylbenzene from lignin oil over $\mathrm{FeOx}$ modified $\mathrm{Ru} / \mathrm{Nb}_{2} \mathrm{O}_{5}$ catalyst. Appl. Catal. B 260:118143. doi: 10.1016/j.apcatb.2019.118143

Li, Y., Zhang, C., Liu, Y., Tang, S., Chen, G., Zhang, R., et al. (2017). Coke formation on the surface of Ni/HZSM- 5 and Ni-Cu/HZSM- 5 catalysts during bio-oil hydrodeoxygenation. Fuel 189, 23-31. doi: 10.1016/j.fuel.2016. 10.047

Liao, Y., Koelewijn, S. F., Van den Bossche, G., Van Aelst, J., Van den Bosch, S., Renders, T., et al. (2020). A sustainable wood biorefinery for low-carbon footprint chemicals production. Science 367, 1385-1390. doi: $10.1126 /$ science.aau1567

Liu, K., Yan, P., Jiang, H., Xia, Z., Xu, Z., Bai, S., et al. (2019). Silver initiated hydrogen spillover on anatase $\mathrm{TiO}_{2}$ creates active sites for selective hydrodeoxygenation of guaiacol. J. Catal. 369, 396-404. doi: 10.1016/j.jcat.2018.11.033

Liu, S., Zheng, W., Fu, J., Alexopoulos, K., Saha, B., and Vlachos, D. G. (2019). Molybdenum oxide-modified iridium catalysts for selective production of renewable oils for jet and diesel fuels and lubricants. ACS Catal. 9, 7679-7689. doi: 10.1021/acscatal.9b02693

Mao, J., Zhou, J., Xia, Z., Wang, Z., Xu, Z., Xu, W., et al. (2017). Anatase TiO2 activated by gold nanoparticles for selective hydrodeoxygenation of guaiacol to phenolics. ACS Catal. 7, 695-705. doi: 10.1021/acscatal.6b02368

Mei, Q., Liu, H., Shen, X., Meng, Q., Liu, H., Xiang, J., et al. (2017). Selective utilization of the methoxy group in lignin to produce acetic acid. Angew. Chem. Int. Ed. 56, 14868-14872. doi: 10.1002/anie.201706846

Mondelli, C., Gözaydin, G., Yan, N., and Pérez-Ramírez, J. (2020). Biomass valorisation over metal-based solid catalysts from nanoparticles to single atoms. Chem. Soc. Rev. 49, 3764-3782. doi: 10.1039/D0CS00130A

Nelson, R. C., Baek, B., Ruiz, P., Goundie, B., Brooks, A., Wheeler, M. C., et al. (2015). Experimental and theoretical insights into the hydrogen-efficient direct hydrodeoxygenation mechanism of phenol over $\mathrm{Ru} / \mathrm{TiO}_{2}$. ACS Catal. 5, 6509-6523. doi: 10.1021/acscatal.5b01554

Phan, T. N., Park, Y.-K., Lee, I.-G., and Ko, C. H. (2017). Enhancement of C-O bond cleavage to afford aromatics in the hydrodeoxygenation of anisole over ruthenium-supporting mesoporous metal oxides. Appl. Catal. A 544, 84-93. doi: 10.1016/j.apcata.2017.06.029

Ren, T. Y., Qi, W., Su, R. X., and He, Z. M. (2019). Promising techniques for depolymerization of lignin into value-added chemicals. ChemCatChem 11, 639-654. doi: 10.1002/cctc.201801428

Sanyal, U., Song, Y., Singh, N., Fulton, J. L., Herranz, J., Jentys, A., et al. (2019). Structure sensitivity in hydrogenation reactions on $\mathrm{Pt} / \mathrm{C}$ in aqueous-phase. ChemCatChem 11, 575-582. doi: 10.1002/cctc.201801344

Shao, Y., Xia, Q., Dong, L., Liu, X., Han, X., Parker, S. F., et al. (2017). Selective production of arenes via direct lignin upgrading over a niobium-based catalyst. Nat. Commun. 8:16104. doi: 10.1038/ncomms16104

Shi, D., Arroyo-Ramírez, L., and Vohs, J. M. (2016). The use of bimetallics to control the selectivity for the upgrading of lignin-derived oxygenates: Reaction of anisole on Pt and PtZn catalysts. J. Catal. 340, 219-226. doi: 10.1016/j.jcat.2016.05.020

Shuai, L., Amiri, M. T., Questell-Santiago, Y. M., Heroguel, F., Li, Y., Kim, H., et al. (2016). Formaldehyde stabilization facilitates lignin monomer production during biomass depolymerization. Science 354, 329-333. doi: $10.1126 /$ science.aaf7810

Shuo, C., Robert, W., Franck, D., Eric, M., and Sébastien, R. (2018). How catalysts and experimental conditions determine the selective hydroconversion of furfural and 5-Hydroxymethylfurfural. Chem. Rev. 118, 11023-11117. doi: 10.1021 acs.chemrev.8b00134

Singh, N., Sanyal, U., Ruehl, G., Stoerzinger, K. A., Gutiérrez, O. Y., Camaioni, D. M., et al. (2020). Aqueous phase catalytic and electrocatalytic hydrogenation of phenol and benzaldehyde over platinum group metals. J. Catal. 382, 372-384. doi: 10.1016/j.jcat.2019.12.034
Song, S., Zhang, J., Gozaydin, G., and Yan, N. (2019). Production of terephthalic acid from corn stover lignin. Angew. Chem. Int. Ed. 58, 4934-4937. doi: $10.1002 /$ anie. 201814284

Song, S., Zhang, J., and Yan, N. (2020). Support effects in the de-methoxylation of lignin monomer 4-propylguaiacol over molybdenum-based catalysts. Fuel Process. Tech. 199:106224. doi: 10.1016/j.fuproc.2019.106224

Sudarsanam, P., Peeters, E., Makshina, E. V., Parvulescu, V. I., and Sels, B. F. (2019). Advances in porous and nanoscale catalysts for viable biomass conversion. Chem. Soc. Rev. 48, 2366-2421. doi: 10.1039/C8CS00452H

Sudarsanam, P., Zhong, R., Van den Bosch, S., Coman, S. M., Parvulescu, V. I., and Sels, B. F. (2018). Functionalised heterogeneous catalysts for sustainable biomass valorisation. Chem. Soc. Rev. 47, 8349-8402. doi: 10.1039/C8CS00410B

Sun, Z., Bottari, G., Afanasenko, A., Stuart, M. C. A., Deuss, P. J., Fridrich, B., et al. (2018a). Complete lignocellulose conversion with integrated catalyst recycling yielding valuable aromatics and fuels. Nat. Catal. 1, 82-92. doi: 10.1038/s41929-017-0007-z

Sun, Z., Fridrich, B., de Santi, A., Elangovan, S., and Barta, K. (2018b). Bright side of lignin depolymerization: toward new platform chemicals. Chem. Rev. 118, 614-678. doi: 10.1021/acs.chemrev.7b00588

Tan, Q., Wang, G., Long, A., Dinse, A., Buda, C., Shabaker, J., et al. (2017). Mechanistic analysis of the role of metal oxophilicity in the hydrodeoxygenation of anisole. J. Catal. 347, 102-115. doi: 10.1016/j.jcat.2017.01.008

Van den Bosch, S., Schutyser, W., Vanholme, R., Driessen, T., Koelewijn, S. F., Renders, T., et al. (2015). Reductive lignocellulose fractionation into soluble lignin-derived phenolic monomers and dimers and processable carbohydrate pulps. Energy Environ. Sci. 8, 1748-1763. doi: 10.1039/C5EE00204D

Wang, P., Jing, Y., Guo, Y., Cui, Y., Dai, S., Liu, X., et al. (2020). Highly efficient alloyed $\mathrm{NiCu} / \mathrm{Nb}_{2} \mathrm{O}_{5}$ catalyst for the hydrodeoxygenation of biofuel precursors into liquid alkanes. Catal. Sci. Technol. 10, 4256-4263. doi: 10.1039/D0CY00684J

Xia, Q., Chen, Z., Shao, Y., Gong, X., Wang, H., Liu, X., et al. (2016). Direct hydrodeoxygenation of raw woody biomass into liquid alkanes. Nat. Commun.7:11162. doi: 10.1007/978-981-10-0218-2

Xin, Y., Dong, L., Guo, Y., Liu, X., Hu, Y., and Wang, Y. (2019a). Correlation of the catalytic performance with $\mathrm{Nb}_{2} \mathrm{O}_{5}$ surface properties in the hydrodeoxygenation of lignin model compound. J. Catal. 375, 202-212. doi: 10.1016/j.jcat.2019.05.007

Xin, Y., Jing, Y., Dong, L., Liu, X., Guo, Y., and Wang, Y. (2019b). Selective production of indane and its derivatives from lignin over a modified niobiumbased catalyst. Chem. Commun. 55, 9391-9394. doi: 10.1039/C9CC04101J

Yang, F., Liu, D., Zhao, Y., Wang, H., Han, J., Ge, Q., et al. (2018). Size dependence of vapor phase hydrodeoxygenation of $\mathrm{m}$-cresol on $\mathrm{Ni} / \mathrm{SiO}_{2}$ catalysts. ACS Catal. 8, 1672-1682. doi: 10.1021/acscatal.7b04097

Zhang, C., and Wang, F. (2020). Catalytic Lignin Depolymerization to Aromatic Chemicals. Acc. Chem. Res. 53, 470-484. doi: 10.1021/acs.accounts.9b00573

Zhang, J., Lombardo, L., Gozaydin, G., Dyson, P. J., and Yan, N. (2018). Single-step conversion of lignin monomers to phenol: Bridging the gap between lignin and high-value chemicals. Chinese J. Catal. 39, 1445-1452. doi: 10.1016/S1872-2067(18)63132-8

Zhang, Z., Song, J., and Han, B. (2017). Catalytic Transformation of Lignocellulose into Chemicals and Fuel Products in Ionic Liquids. Chem. Rev. 117, 6834-6880. doi: 10.1021/acs.chemrev.6b00457

Conflict of Interest: The authors declare that the research was conducted in the absence of any commercial or financial relationships that could be construed as a potential conflict of interest.

Copyright $(0) 2020$ Jing and Wang. This is an open-access article distributed under the terms of the Creative Commons Attribution License (CC BY). The use, distribution or reproduction in other forums is permitted, provided the original author $(s)$ and the copyright owner(s) are credited and that the original publication in this journal is cited, in accordance with accepted academic practice. No use, distribution or reproduction is permitted which does not comply with these terms. 